\title{
Tumor Control and Quality of Life in Skin Cancer Patients With Extensive Multilayered Nasal Defects
}

\author{
Michaela Plath (iD · Hannah M. Thielen (D) - Ingo Baumann (iD · Karim Zaoui (i) · Philippe A. Federspil (D) \\ Department of Otorhinolaryngology, Heidelberg University Hospital, Heidelberg, Germany
}

Objectives. The reconstruction after nasal skin cancer (NSC) resection is often practiced differently. The objective of this study is to evaluate the influence of patient-, tumor- and management-related factors on the role of surgery and choice of reconstruction.

Methods. This was a monocentric retrospective study of patients who were diagnosed with a NSC (squamous cell or basal cell carcinoma) and suffered from an extended defect after ablative surgery between 2003 and 2013. Twenty-five patients were included. Tumors were staged using the Union for International Cancer Control (eighth edition) TNM classification for primary cutaneous skin cancer of the head and neck. Preferred treatment was surgery in all patients. Health-related quality of life (HRQoL) measurement was evaluated by one generic (36-Item Short Form Health Survey [SF-36]) and two organ-specific questionnaires (Rhinoplasty Outcome Evaluation [ROE] and Functional Rhinoplasty Outcome Inventory 17 [FROI-17]) after therapy. Survival data were estimated by the Kaplan-Meier method and statistical analysis was performed by log-rank, analysis of variance, Levene's and $t$-tests. The median follow-up time was 2.1 years.

Results. According to the Union for International Cancer Control classification, 13 of 25 tumors were staged as pT1 (52\%), four as pT2 $(16 \%)$, seven as pT3 $(28 \%)$ and one as pT4a $(4 \%)$. Seventy-two percent of patients $(n=18)$ chose plastic reconstruction, and for the remaining $28 \%(n=7)$ of the patients opted for an implant-retained prosthesis. The overall survival was $69.5 \%$ after 5 years, the 5 -year recurrence-free survival was $90.9 \%$ and the 5 -year disease-specific survival was $100 \%$. There was no significant difference in the HRQoL outcome between both rehabilitation methods.

Conclusion. Surgery in NSC gives an excellent oncologic prognosis. Nasal reconstruction and prostheses are both very viable options depending on tumor stage and biology, the patient's wishes as well as the experience of the surgeon.

Keywords. Skin Neoplasms; Surgical Oncology; Nasal Surgical Procedures; Bone-Anchored Prosthesis; Quality of Life

\section{INTRODUCTION}

Skin cancer is the most common malignant disease. Basal cell carcinomas (BCC) and cutaneous squamous cell carcinomas (cSCC) are the major histological types of nonmelanoma skin cancer. cSCC is more aggressive than BCC and is often locally

\footnotetext{
- Received February 6, 2019

Revised May 26, 2019

Accepted June 10, 2019

- Corresponding author: Philippe A. Federspil

Department of Otorhinolaryngology, Heidelberg University Hospital, Im Neuenheimer Feld 400, D-69120 Heidelberg, Germany

Tel: +49-6221-566705, Fax: +49-6221-5633637

E-mail: federspil@med.uni-heidelberg.de
}

recurrent and sometimes metastasizes to local and locoregional lymph nodes. In contrast, metastasis of BCC is very rare with an incidence of less than $0.01 \%$ [1,2]. BCCs are prone to locally aggressive growth with invasion of the soft tissue, cartilage, and bone. Approximately $75 \%-80 \%$ of BCC occur in the head and neck region [3]. In contrast, $\mathrm{CSCC}$ has shifted from the head and neck to the extremities in the last decades. However, the incidence of both BCC and cSCC in the head and neck is rapidly increasing. This is attributed to genetic factors, excessive exposure to radiation (ultraviolet B-rays [UVB], artificial, and natural radiation), and prolonged life expectancy [4-6]. The prognosis of BCC and CSCC depends on tumor localization, surgical margins, histological subtype, gene expression, immunosuppression,

Copyright $\odot 2020$ by Korean Society of Otorhinolaryngology-Head and Neck Surgery.

This is an open-access article distributed under the terms of the Creative Commons Attribution Non-Commercial License (http://creativecommons.org/licenses/by-nc/4.0)

which permits unrestricted non-commercial use, distribution, and reproduction in any medium, provided the original work is properly cited. 
previous incomplete treatment, and recurrence [7].

BCC and cSCC are often highly aggressive and destructive, especially in the orbit and nose; therefore a combination of optimal tumor control and best possible cosmesis after surgery is very important. Therapies for BCC and cSCC of the nose include surgery with rehabilitation, primary radiochemotherapy, brachytherapy, or a combination of treatments [8-14]. Moreover, recurrent or unresectable BCC can be treated with Vismodegib. The nose is a prominent landmark in the center of the face, has a complex three-layered structure (skin, cartilage or bone, and mucosa) and has three-dimensional contours, which makes reconstructing the nose a challenge for the head and neck surgeon $[15,16]$. Rehabilitation after ablation may be achieved by surgical reconstruction with autologous material or by fitting a boneanchored nasal prosthesis. The type of rehabilitation depends on the tumor stage and biology, as well as the wishes of the patient. Nasal dysfunction or an unsatisfactory aesthetic outcome may occur after reconstruction of multilayered nasal defects. Although the reconstruction of superficial tumors with skin defects can also be challenging, in this study we only investigate deep infiltrating and multilayered tumors $[17,18]$.

To our knowledge, the different rehabilitation options in nasal skin cancer (NSC) patients with extensive multilayered defects have not been investigated alone so far. In this single center study, we compared patients' Health-related quality of life (HRQoL) following the reconstruction of extended defects after nasal cancer resection by plastic reconstruction versus use of an implant-retained prosthesis.

\section{MATERIALS AND METHODS}

This study was performed in accordance with the guidelines of the Declaration of Helsinki on biomedical research involving human subjects, and the study protocol was approved by the local Ethics Committee of Medical Faculty, Heidelberg University Hospital, and informed consent for study and publication was obtained from all individual participants included in the study.

Nasal cancer patients with newly diagnosed nonmelanoma NSC requiring ablative surgery resulting in extensive multilayered nasal defects at the Department of Otolaryngology, Head

\section{H I G H L I G H T T S}

- Surgery in advanced nasal skin cancer patients results in an excellent prognosis.

- Quality of life is equal in nasal reconstruction and prosthetic rehabilitation for extensive skin cancer defects.

- Nasal reconstruction and prostheses are both very viable options depending on tumor stage and biology, patient's wishes as well as the experience of the surgeon. and Neck Surgery at the Heidelberg University Hospital between 2003 and 2013 were included in the study [19]. Patients with cancer of the nasal vestibule or nasal cavity were excluded [20]. Treatment options were discussed by a multidisciplinary tumor board. In accordance with National Comprehensive Cancer Network guidelines, surgical resection was the preferred treatment option. A detailed presurgical clinical examination with complete skin inspection to exclude other malignant skin tumors was performed by experienced physicians (KZ and $\mathrm{PAF})$, together with ultrasound examination of the neck. An additional computed tomography (CT) scan of the mid-face with thin-sliced images was performed for advanced tumors. A complementary CT of the neck and thorax and ultrasound examination of the abdomen was used for staging. Tumor resection was performed by diathermy to reduce bleeding and to avoid the need for vasoconstrictor agents. Depending on tumor localization, extension, and infiltration depth, a two-layer resection (skin and cartilage/bone), or full thickness (three-layer) excision was carried out by a partial or total rhinectomy. Selective neck dissection was performed in the cSCC group in suspected cervical lymph node metastases only. Aesthetic and functional rehabilitation was achieved by surgical multi-layer reconstruction or prosthetic restoration. Depending on the tumor stage, Karnofsky performance status and age (older patients often preferred a prosthetic restoration), the reconstruction methods were discussed with the patient. The preferred method for surgical reconstruction was the paramedian forehead flap to meet the subunit principle. Surgery was performed by the senior surgeon (PAF).

For all patients, clinical and follow-up data (sex, age, TNM classification, histopathological differentiation, treatment modalities, and outcome) were recorded. Tumors were staged according to the Union for International Cancer Control (eighth edition). Overall survival (OS), disease-specific survival (DSS), and recurrence-free survival (RFS) were statistically estimated by the Kaplan-Meier method using IBM SPSS ver. 22.0 (IBM Corp., Armonk, NY, USA).

Patients completed one generic questionnaire (36-Item Short Form Health Survey [SF-36]) and two organ-specific questionnaires (Rhinoplasty Outcome Evaluation [ROE] and Functional Rhinoplasty Outcome Inventory 17 [FROI-17]) after treatment between 2013 and 2015. The SF-36 Health Survey is composed of eight subgroups: physical functioning, physical role functioning, bodily pain, general health, vitality, social functioning, emotional role functioning, and mental health (scales and scoring are reflected in the SF-36 Health Survey Manual and Interpretation Guide). The ROE is composed of six items and focuses more on aesthetic aspects. A higher ROE score indicates higher satisfaction. The FROI-17 contains 17 items and measures more functional aspects [21,22]. A higher FROI-17 score indicates less satisfaction. Differences between subgroups were tested by $\log$-rank, analysis of variance, Levene's, and $t$-tests. In all statis- 
Table 1. Surgical and clinicopathological characteristics of the study population

\begin{tabular}{|c|c|c|c|}
\hline Characteristics & $\begin{array}{l}\text { Entire } \\
\text { cohort } \\
(n=25)\end{array}$ & $\begin{array}{l}\text { Prosthesis } \\
\text { cohort } \\
(\mathrm{PR}, \mathrm{n}=7)\end{array}$ & $\begin{array}{c}\text { Reconstruction } \\
\text { cohort } \\
(\mathrm{SR}, \mathrm{n}=18)\end{array}$ \\
\hline Age (yr) & $73(52-93)$ & $85(74-92)$ & 68 (52-93) \\
\hline \multicolumn{4}{|l|}{ Sex } \\
\hline Male & $15(60.0)$ & $3(42.9)$ & $12(66.7)$ \\
\hline Female & $10(40)$ & $4(57.1)$ & $6(33.3)$ \\
\hline \multicolumn{4}{|l|}{ Histology } \\
\hline $\mathrm{BCC}$ & $20(80)$ & $5(71.4)$ & $15(83.3)$ \\
\hline cSCC & $5(20)$ & $2(28.6)$ & $3(16.7)$ \\
\hline \multicolumn{4}{|l|}{ T stage } \\
\hline $\mathrm{T} 1 / 2$ & $17(68.0)$ & $3(42.9)$ & $14(77.8)$ \\
\hline T3/4 & $8(32.0)$ & $4(57.1)$ & $4(22.2)$ \\
\hline \multicolumn{4}{|l|}{ N stage } \\
\hline No & $25(100)$ & $7(100)$ & $18(100)$ \\
\hline \multicolumn{4}{|l|}{ M stage } \\
\hline Mo & $25(100)$ & $7(100)$ & $18(100)$ \\
\hline \multicolumn{4}{|c|}{ Questionnaire (FROI-17, ROE, and SF-36) } \\
\hline No response & $7(28.0)$ & $1(14.3)$ & $6(33.3)$ \\
\hline Response & $11(44.0)$ & $2(28.6)$ & $9(50.0)$ \\
\hline Excluded due to death & $7(28.0)$ & $4(57.1)$ & $3(16.7)$ \\
\hline 5-Year overall survival rate (\%) & 69.5 & 53.6 & 77.2 \\
\hline $\begin{array}{l}\text { 5-Year disease-specific } \\
\text { survival rate }(\%)\end{array}$ & 100 & 100 & 100 \\
\hline $\begin{array}{l}\text { 5-Year recurrence-free } \\
\text { survival rate (\%) }\end{array}$ & 90.9 & 100 & 85.7 \\
\hline
\end{tabular}

Values are presented as mean (range) or number (\%).

$\mathrm{PR}$, prosthetic rehabilitation; SR, surgical reconstruction; BCC, basal cell carcinomas; cSCC, cutaneous squamous cell carcinomas; FROI-17, Functional Rhinoplasty Outcome Inventory 17; ROE, Rhinoplasty Outcome Evaluation; SF-36, 36-Item Short Form Health Survey.

tical tests, a $P$-value $\leq 0.05$ was considered statistically significant.

\section{RESULTS}

Twenty-five patients were included in the analysis. Baseline patient characteristics are presented in Table 1. Patient age ranged from 52 years to 93 years, with a mean age of 73 years. The sex ratio was 1.5 in favor of men (10 women and 15 men). Five out of 25 patients were diagnosed with a cSCC (20\%) and 20 of 25 with a BCC $(80 \%)$ of the nose. Four out of five cSCCs $(80 \%)$ were moderately differentiated (grade G2) and for one cSCC $(20 \%)$, no differentiation was given (Gx). One cSCC was staged as pT1 $(20 \%)$ and the remaining four as pT3 $(80 \%)$. For BCC of the nose, 12 of $20(60 \%)$ were classified as pT1, four of 20 $(20 \%)$ as pT2, three of $20(15 \%)$ as pT3, and one of $20(5 \%)$ as pT4a (Table 1). Five tumors were removed by two-layer skin and cartilage/bone resections, which preserved the mucosal layer.Twenty tumors needed full thickness, three-layered resections with 13 partial and seven total rhinectomies. In 18 of 25 pa- tients $(72 \%)$, nasal reconstruction was performed using a paramedian forehead flap. These 18 patients had a two-layer defect in five of 18 cases $(27.8 \%)$ and a three-layer defect in 13 of 18 cases $(72.2 \%)$. The inner lining and framework of the 13 threelayer defects was reconstructed using an anterior septal mucoperichondrious flap together with conchal cartilage grafts. Seven out of $25(28 \%)$ patients were fitted with an implant-retained nasal prosthesis using the Epiplating implant system (Medicon eG, Tuttlingen, Germany) (Fig. 1). No major postoperative complications were observed in our cohort (prosthetic rehabilitated or surgical reconstructed patients).

All resections achieved a histopathological R0 resection. In one cSCC patient with suspected lymph node status (based on imaging), a concomitant bilateral neck dissection was performed and resulted in a pN0 classification. Two out of five CSCC patients $(40 \%)$ had advanced stage tumors with infiltration of the upper lip and/or premaxillary bone, therefore received adjuvant radiation therapy.

The median follow-up time was 2.1 years (range, 0.5 to 12.3 years). Seven deaths were recorded. No deaths were related to NSC. Causes of death were second malignancies (non-Hodgkin lymphoma and non-small cell lung cancer) or cardiovasculary/ pulmonary disease. One local relapse $(4 \%)$ occurred in a T1 BCC patient 3.05 years after resection and reconstruction with a paramedian forehead flap.The patient declined further surgery and opted for definitive radiotherapy. To date, the patient is tumor free.

The 5-year OS was $69.5 \%$ for the entire cohort and no statistically significant differences were observed between the BCC and CSCC groups (5-year OS: 70.7\% [BCC cohort] and 60\% [cSCC cohort]; log-rank $P=0.54$ ) (Fig. 2). Furthermore, 5-year OS was not significantly different between surgically reconstructed patients $(77.2 \%)$ and prosthetically rehabilitated patients (53.6\%) (log-rank $P=0.15$ ). Five-year RFS was not significantly different between the reconstruction cohort $85.7 \%$ and prosthesis cohort $100 \%$ ( $\log$ rank $P=0.45)$. The 5 -year RFS for the entire study population was $90.9 \%$ (BCC, $87.5 \%$; cSCC, $100 \%$; log-rank $P=0.54$ ) (Fig. 2). The DSS was $100 \%$. Data on HRQoL was collected for an average 1.7 years after surgery. At the time of the survey, 18 of 25 patients (72\%) were still alive. Eleven out of $18(61 \%)$ living patients completed all questionnaires. The nasal defects of two patients were prosthetically rehabilitated $(18.2 \%)$ and the defects were surgically reconstructed in nine patients $(81.8 \%)$.

CSCC patients (average ROE score, 81.3; standard deviation [SD], 20.6) had a higher HRQoL score than BCC patients (average ROE score, 70.8; SD, 20.1), but this difference was not significant. FROI-17 self-confidence subscales were very low for both tumor types, indicating a high degree of self-confidence. Regarding the SF-36 questionnaire, physical functioning scores were significantly lower in the BCC group (average FROI-17 score, 61.9; SD, 31.7) than the cSCC group (91.7; SD, 10.4; $P=$ 

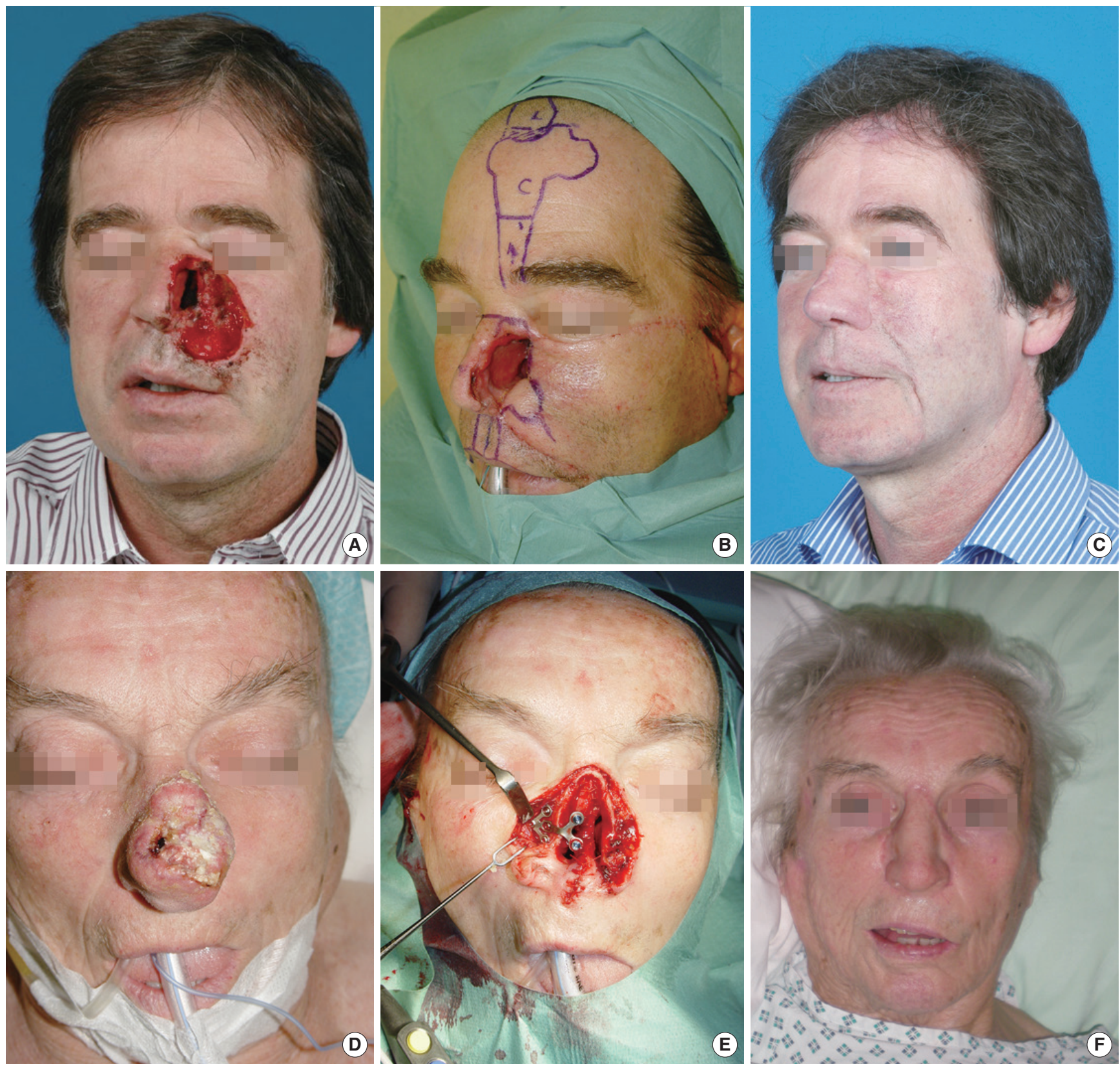

Fig. 1. (A-C) Partial rhinectomy and reconstruction with a paramedian forehead flap, anterior based septal mucoperichondrious flap, and cartilage graft. (D-F) Total rhinectomy followed by reconstruction with an implant-retained nasal prosthesis (nasal plate of the Epiplating System by Medicon eG, Tuttlingen, Germany; anaplastologist Jörn Brom, Heidelberg, Germany).

0.044) (Table 2, Fig. 3). No significant differences were observed in all HRQoL questionnaire scores between surgical reconstruction versus prosthetic rehabilitation and early (T1/2) versus advanced (T3/4) tumor stages. The SF-36 scores in the NSC patient group were significantly lower than those in the normally distributed reference population $(\mathrm{n}=2,900)$ for physical functioning $(P=0.049)$ and social functioning $(P<0.001)$ (Fig. 3$)$. The means and standard deviation values for all questionnaires for all patient subgroups are shown in Table 2 .

\section{DISCUSSION}

The therapy of choice for NSC is surgery. However, the nose has a delicate and complex multilayered structure and prominent localization, which makes reconstruction of post-surgical defects challenging. Functional and aesthetic nasal problems may arise following surgery [23]. Established guidelines for nasal reconstruction are still lacking $[24,25]$. HRQoL scores are increasingly indispensable for measuring aesthetic and functional rehabilita- 
OS
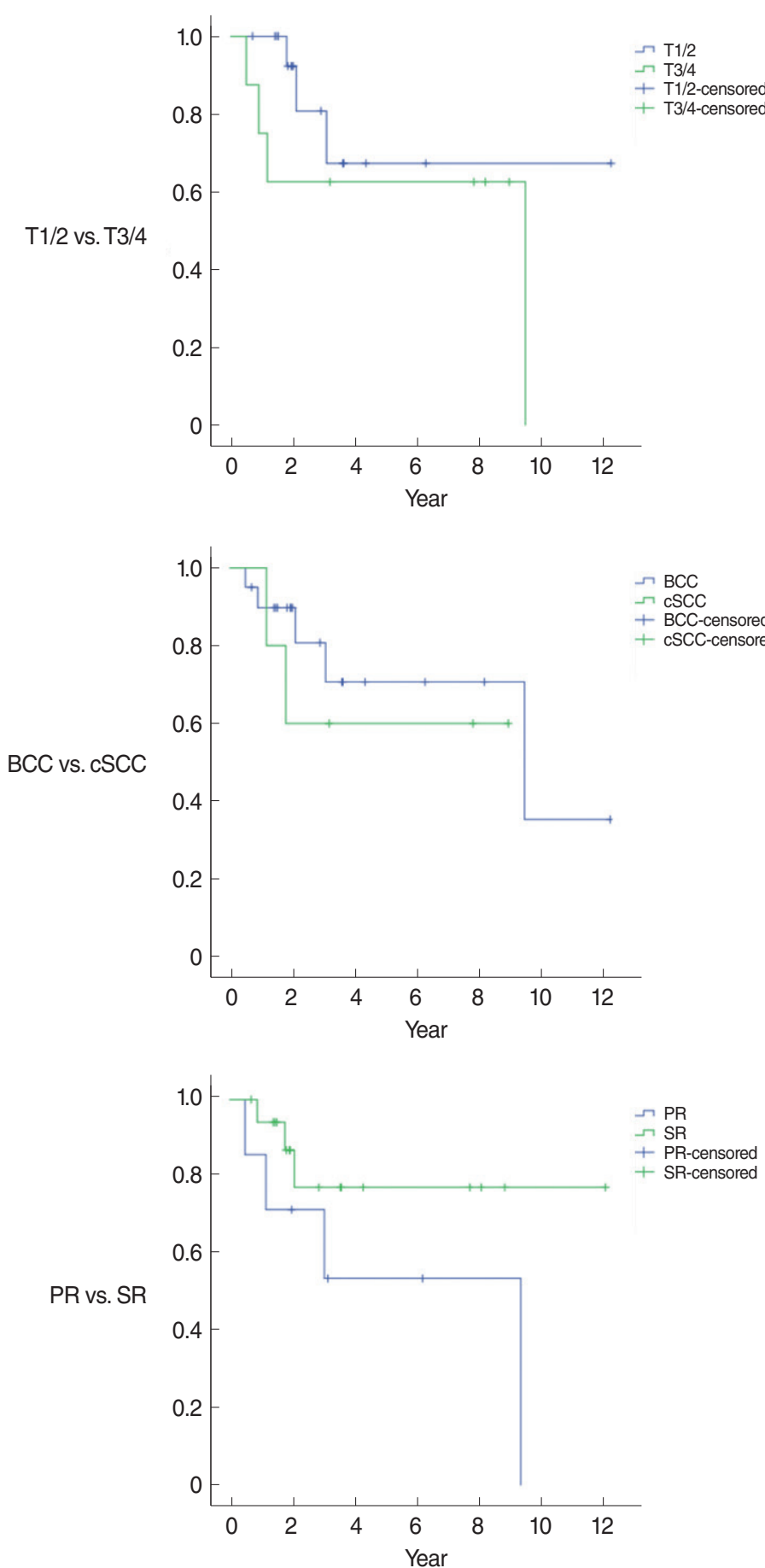

RFS
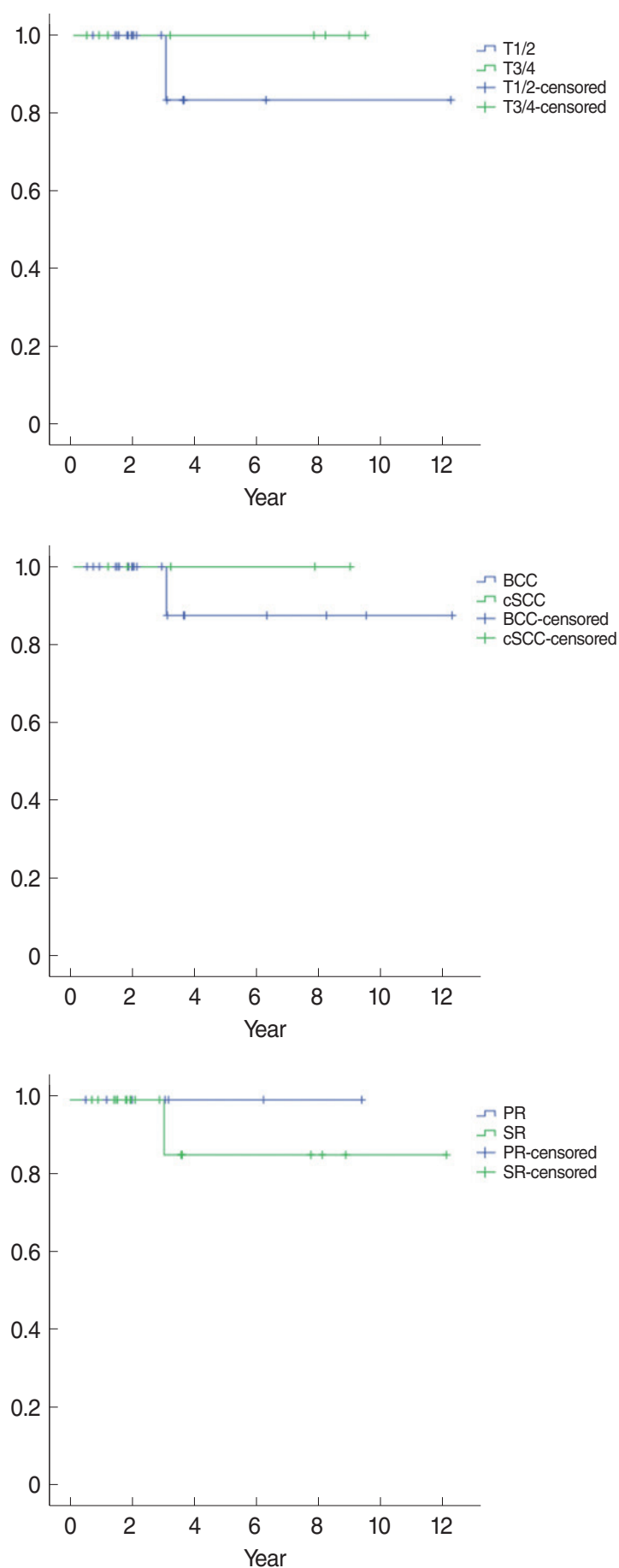

Fig. 2. Kaplan-Maier plots for overall survival (OS) and recurrence-free survival (RFS) depending on T1/2 vs. T3/4, basal cell carcinoma (BCC) vs. cutaneous squamous cell carcinoma (cSCC), prosthetic rehabilitation (PR) vs. surgical reconstruction (SR). Disease-specific survival was $100 \%$ (not shown).

tion after surgery. However, there are still no HRQoL data for patients with multilayered defects in an area as aesthetically prominent as the nose after surgery to treat skin cancer.

So far, only two studies have investigated HRQoL in patients after radical nasal tumor resection with prosthetic rehabilitation alone, and only two studies have evaluated patients after surgical nasal reconstruction alone [26-29]. These studies used the modified surveys University of Washington QoL (UWQoL) and 
Table 2. FROI-17, ROE, and SF-36 scales

\begin{tabular}{|c|c|c|c|}
\hline Variable & $\begin{array}{l}\text { Prosthetic } \\
\text { rehabilitation } \\
(n=7)\end{array}$ & $\begin{array}{c}\text { Surgical } \\
\text { reconstruction } \\
(n=18)\end{array}$ & $P$-value \\
\hline \multicolumn{4}{|l|}{ FROI-17 } \\
\hline Overall score & $15.0 \pm 0.0$ & $25.6 \pm 29.2$ & 0.750 \\
\hline Nasal symptom & $10.0 \pm 12.4$ & $22.2 \pm 20.8$ & 0.610 \\
\hline General symptom & $20.0 \pm 14.4$ & $21.4 \pm 29.1$ & 0.965 \\
\hline Self-confidence & $0.0 \pm 0.0$ & $20.0 \pm 32.7$ & 0.588 \\
\hline ROE & $79.2 \pm 0.0$ & $72.4 \pm 20.6$ & 0.766 \\
\hline \multicolumn{4}{|l|}{ SF-36 } \\
\hline Physical functioning & $55.0 \pm 35.4$ & $73.3 \pm 30.4$ & 0.469 \\
\hline Physical role functioning & $50.0 \pm 70.7$ & $66.7 \pm 50.0$ & 0.695 \\
\hline Bodily pain & $94.4 \pm 7.9$ & $72.8 \pm 31.5$ & 0.378 \\
\hline General health & $52.5 \pm 3.5$ & $64.4 \pm 26.2$ & 0.558 \\
\hline Vitality & $55.0 \pm 0.0$ & $70.0 \pm 28.9$ & 0.640 \\
\hline Social functioning & $43.8 \pm 8.8$ & $50.0 \pm 11.6$ & 0.503 \\
\hline Emotional role functioning & $66.7 \pm 47.1$ & $79.2 \pm 39.6$ & 0.707 \\
\hline \multirow[t]{2}{*}{ Mental health } & $72.0 \pm 0.0$ & $69.0 \pm 16.0$ & 0.864 \\
\hline & $\operatorname{BCC}(n=20)$ & $\operatorname{cSCC}(n=5)$ & \\
\hline \multicolumn{4}{|l|}{ FROI-17 } \\
\hline Overall score & $25.8 \pm 29.1$ & $13.8 \pm 0.0$ & 0.717 \\
\hline Nasal symptom & $21.7 \pm 21.2$ & $13.3 \pm 0.0$ & 0.730 \\
\hline General symptom & $26.3 \pm 29.7$ & $6.3 \pm 8.8$ & 0.404 \\
\hline Self-confidence & $21.7 \pm 35.4$ & $5.0 \pm 7.1$ & 0.553 \\
\hline ROE & $70.8 \pm 20.1$ & $81.3 \pm 20.6$ & 0.541 \\
\hline \multicolumn{4}{|l|}{ SF-36 } \\
\hline Physical functioning & $61.9 \pm 31.7$ & $91.7 \pm 10.4$ & 0.044 \\
\hline Physical role functioning & $62.5 \pm 51.8$ & $66.7 \pm 57.7$ & 0.910 \\
\hline Bodily pain & $72.2 \pm 33.6$ & $88.9 \pm 11.1$ & 0.248 \\
\hline General health & $57.1 \pm 25.5$ & $73.3 \pm 17.6$ & 0.352 \\
\hline Vitality & $63.3 \pm 30.9$ & $78.3 \pm 20.2$ & 0.478 \\
\hline Social functioning & $48.2 \pm 13.4$ & $50.0 \pm 0.0$ & 0.829 \\
\hline Emotional role functioning & $66.7 \pm 43.0$ & $100.0 \pm 0.0$ & 0.086 \\
\hline \multirow[t]{2}{*}{ Mental health } & $66.0 \pm 17.7$ & $76.0 \pm 4.0$ & 0.380 \\
\hline & $\begin{array}{c}\text { NSC cohort } \\
(n=25)\end{array}$ & $\begin{array}{c}\text { SF-36 cohort } \\
(n=2,900)\end{array}$ & \\
\hline \multicolumn{4}{|l|}{ SF-36 } \\
\hline Physical functioning & $70.0 \pm 30.3$ & $84.2 \pm 23.8$ & 0.049 \\
\hline Physical role functioning & $63.6 \pm 50.5$ & $80.6 \pm 34.5$ & 0.292 \\
\hline Bodily pain & $76.8 \pm 29.6$ & $77.0 \pm 28.5$ & 0.978 \\
\hline General health & $62.0 \pm 23.7$ & $64.1 \pm 23.5$ & 0.777 \\
\hline Vitality & $68.3 \pm 27.5$ & $61.9 \pm 19.1$ & 0.316 \\
\hline Social functioning & $48.8 \pm 10.9$ & $87.7 \pm 19.5$ & $<0.001$ \\
\hline Emotional role functioning & $76.7 \pm 38.7$ & $87.7 \pm 29.0$ & 0.228 \\
\hline Mental health & $69.3 \pm 15.0$ & $72.9 \pm 17.2$ & 0.541 \\
\hline
\end{tabular}

Values are presented as mean \pm standard deviation.

FROI-17, ROE, and SF-36 scales after prosthetic rehabilitation $(n=7)$ vs surgical reconstruction $(n=18)$ in all patients $(T 1-4), B C C(n=20)$ vs. cSCC patients $(n=5)$, and NSC cohort ( $n=25)$ vs. the normally distributed SF-36 reference population $(n=2,900)$. A higher ROE score indicates higher satisfaction. A higher FROI-17 score indicates lower satisfaction. $P<0.05$ were considered statistically significant.

FROI-17, Functional Rhinoplasty Outcome Inventory 17; ROE, Rhinoplasty Outcome Evaluation; SF-36, 36-Item Short Form Health Survey; SD, standard deviation; BCC, basal cell carcinomas; cSCC, cutaneous squamous cell carcinomas; NSC, nasal skin cancer.
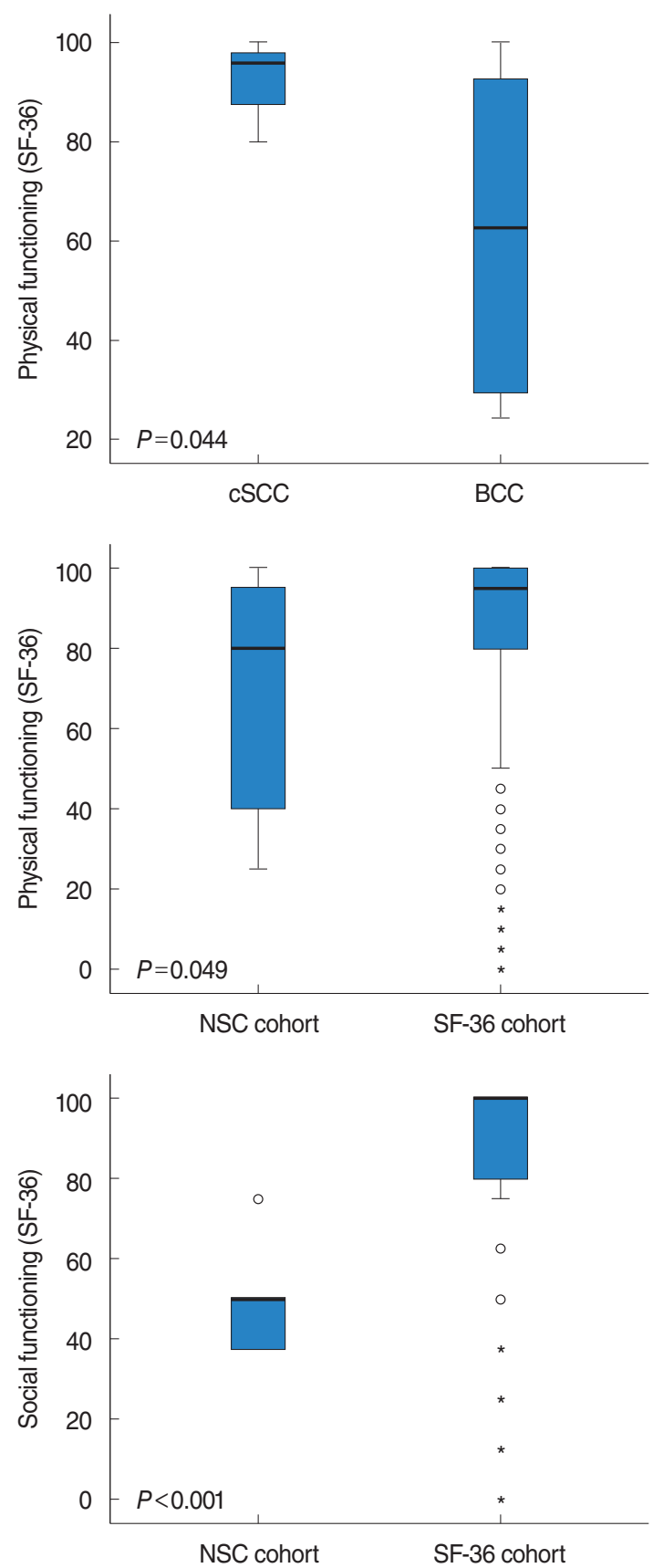

Fig. 3. Box-plot analysis showing the 36-Item Short Form Health Survey (SF-36) subscores $(P<0.05)$ comparing sub-cohort (cutaneous squamous cell carcinoma [cSCC] versus basal cell carcinoma [BCC]; surgical reconstruction versus prosthetic rehabilitation, T1/2 versus T3/4, and in the SF-36 to the norm-distributed patient cohort). A higher SF-36 score indicates higher satisfaction. Only significant differences are presented. NSC, nasal skin cancer.

the Nasal Appearance and Function Evaluation Questionnaire (NAFEQ) $[26,30,31]$. The UWQoL mainly focuses on social and physical function, such as mood, salivation, anxiety, taste, speech, shoulder function, chewing, swallowing, recreation, activity, appearance, and pain. The NAFEQ questionnaire evalu- 
Table 3. Comparison of advantage and disadvantage in prosthetic rehabilitation versus surgical reconstruction

\begin{tabular}{|c|c|c|}
\hline Variable & Prosthetic rehabilitation & Surgical reconstruction \\
\hline Advantage & $\begin{array}{l}\text { - Simple and fast surgical procedure for implant placement } \\
\text { (operating time approximately } 20-30 \text { minutes) } \\
\text { - No donor site morbidity/scars } \\
\text { - Short rehabilitation time (fitting after a healing period of } 6 \text { weeks) } \\
\text { - Predictable cosmesis of prosthesis } \\
\text { - Prosthesis may be changed according to patient wishes. } \\
\text { - Ease of oncological follow-up to detect local recurrence }\end{array}$ & $\begin{array}{l}\text { - Psychological benefit of using patient's own tissue } \\
\text { - No need for maintenance or specialized care } \\
\text { - Defect is eliminated and no longer visible. } \\
\text { - Follows color change of adjacent skin with temperature, emotion } \\
\text { and sun exposure }\end{array}$ \\
\hline Disadvantage & $\begin{array}{l}\text { - Prothesis is a "foreign body." } \\
\text { - Patients keep the defect. } \\
\text { - Risk of losing the prosthesis with inadvertent contact } \\
\text { - Prosthesis is removed for sleeping (patient wears a light } \\
\text { bandage). } \\
\text { - Prosthesis may exhibit color mismatch with seasonal changing } \\
\text { - complexion or cigarette smoke. } \\
\text { - Necessity of a new prosthesis every } 2 \text { years due to degradation } \\
\text { - Cost for initial and repetitive manufacturing } \\
\text { - Personal hygiene for percutaneous parts of implants } \\
\text { (however minimal for nasal implants) } \\
\text { - Magnets have to be temporarily removed for MRI } \\
\text { (titanium implants are MRI conditional). }\end{array}$ & $\begin{array}{l}\text { - Multiple stages of surgical reconstruction under general } \\
\text { - Lnesthesia with longer operation time } \\
\text { - Posser healing time with three surgical stages of 3-6 months } \\
\text { in irradiated patients and smokers } \\
\text { - Possible need for secondary refinement surgery } \\
\text { - Additional scars outside the nasal region } \\
\text { - Malignant precursor lesion may be transposed } \\
\text { (field cancerization with UV exposure). } \\
\text { - Cosmetic result less predictable } \\
\text { - Oncological follow-up less easy } \\
\text { (may need endoscopy and imaging) }\end{array}$ \\
\hline
\end{tabular}

UV, ultraviolet; MRI, magnetic resonance imaging.

ates aesthetic and functional outcomes.

However, the only validated HRQoL questionnaires for conventional rhinoplasty are the FROI-17 and the ROE [32,33]. Similar to the NAFEQ, the organ-specific FROI-17 evaluates both functional and aesthetic outcomes after rhinoplasty. The ROE focuses on the cosmetic outcome and the SF-36 assesses social and physical functions.

Twenty-five patients with nonmelanoma NSC were included in this study. There may be some degree of referral bias, which cannot be completely controlled, but surgery is the treatment of choice in our institution. A detailed comparison of major advantages and disadvantages of both rehabilitation strategies is given in Table 3 showing that the nasal reconstruction and prostheses are both very viable options depending on tumor stage, biology, and the patient's wishes as well as the experience of the surgeon. To our knowledge, this is the first study to compare two different rehabilitation strategies (prosthetic rehabilitation versus surgical reconstruction) after surgical treatment of advanced NSC with HRQoL analysis. Due to the small number of patients, valid statements on differences in age and gender regarding the HRQoL outcome could not be addressed.

The ROE scores ranged between 70.8 and 81.25 , indicating that the aesthetic HRQoL was similar in all subgroups. Compared with average scores of 58.8-83.3 after conventional rhinoplasty, our subgroup ROE findings were high [33-36]. Although the comparison between conventional rhinoplasty and NSC patients is limited, this patient-reported aesthetic result is very satisfactory and quite astonishing [22].

In contrast to the ROE, a higher FROI-17 score indicates lower satisfaction. The FROI-17 includes functional questions, which complement the aesthetic assessment of the ROE. For the subcohort analysis (cSCC vs. BCC; surgical reconstruction versus prosthesis rehabilitation;T1/2 vs. T3/4), the overall FROI-17 and the subscores general symptoms, nasal symptoms, and self-confidence did not differ significantly.

In the generic SF-36 questionnaire, physical functioning scores were higher in cSCC patients (91.7) than BCC patients (61.9). This might be partly due to different age distribution or different postoperative expectations. We compared our data with a normally distributed reference cohort (which was included in the validation of the SF-36). Physical functioning was good in our NSC patients, but significantly worse than the reference patient cohort. Although organ specific HRQoL were satisfactory, significantly low physical and social functioning scores may indicate restrictions in everyday life. Age and orthopedic disabilities may be responsible for the reduced HRQoL score for the NSC group compared to reference cohort. However, these were not examined due to the low number of the NSC cohort. We believe that the excellent organ-specific HRQoL outcome we observed is a result of our dedicated multidisciplinary approach with extensive rehabilitation counselling before ablative surgery is performed.

The strength of the study that it is the first to address HRQoL in advanced NSC patients. There are, of course, also limitations of this study. Obviously, the study cohort is small, which is due to the low incidence of patients with this particular tumor entity being that far locally advanced to require multilayered excision. There might be a referral bias to this study, as some patients might have been sent for radiotherapy, because they declined rhinectomy. However, we estimate that the proportion is mini- 
mal, because the institutional preference in this situation is surgery. Moreover, the assignment of patients the rehabilitation strategy was based on patients' preference and oncological factors as stage, tumor biology and risk factors on histology, and not in a randomized controlled fashion. However, we believe that such a trial would be difficult to conduct, as these patients most likely declined randomization.

Overall oncological outcome is good for nonmelanoma NSC. However, extensive multilayer resections are sometimes necessary to cure the patient which may have high physiological impact on the patients and affect their HRQoL. Despite the worse overall HRQoL outcome (SF-36) than in the control cohort, in terms of organ-specific HRQoL (ROE and FROI-8), we observed a high degree of satisfaction. We believe that this might be a merit of our dedicated multidisciplinary approach with extensive counselling of all rehabilitation options before ablative surgery is performed. Interestingly, the HRQoL outcome between both rehabilitation methods had been comparable. Therefore patient's preference and the experience of the surgeon should be considered when choosing the reconstruction method.

\section{CONFLICT OF INTEREST}

No potential conflict of interest relevant to this article was reported.

\section{ORCID}

Michaela Plath

https://orcid.org/0000-0002-8988-1398

Hannah M.Thielen

https://orcid.org/0000-0003-1923-3368

Ingo Baumann

https://orcid.org/0000-0001-6945-2601

Karim Zaoui

https://orcid.org/0000-0002-6676-2273

Philippe A. Federspil https://orcid.org/0000-0002-2537-0185

\section{AUTHOR CONTRIBUTIONS}

Conceptualization: PAF, KZ, MP, HMT. Data curation: MP, HMT, KZ. Formal analysis: MP, HMT, KZ, IB, PAF. Methodology: HMT, KZ, IB, PAF. Project administration: KZ, PAF. Visualization: MP, HMT, KZ. Writing - original draft: MP, KZ, PAF. Writing - review \& editing: MP, KZ, PAF.

\section{REFERENCES}

1. Brana I, Siu LL. Locally advanced head and neck squamous cell cancer: treatment choice based on risk factors and optimizing drug prescription. Ann Oncol. 2012 Sep;23 Suppl 10:x178-85.

2. Lee K, McKean ME, McGregor IA. Metastatic patterns of squamous carcinoma in the parotid lymph nodes. Br J Plast Surg. 1985 Jan;
38(1):6-10.

3. Wu S, Han J, LiWQ, LiT, Qureshi AA. Basal-cell carcinoma incidence and associated risk factors in U.S. women and men. Am J Epidemiol. 2013 Sep;178(6):890-7.

4. Muzic JG, SchmittAR,Wright AC,Alniemi DT, Zubair AS, Olazagasti Lourido JM, et al. Incidence and trends of basal cell carcinoma and cutaneous squamous cell carcinoma: a population-based study in Olmsted County, Minnesota, 2000 to 2010. Mayo Clin Proc. 2017 Jun;92:890-8.

5. Bath-Hextall F, Leonardi-Bee J, Smith C, Meal A, Hubbard R.Trends in incidence of skin basal cell carcinoma: additional evidence from a UK primary care database study. Int J Cancer. 2007 Nov;121(9): 2105-8.

6. Preston DS, Stern RS. Nonmelanoma cancers of the skin. N Engl J Med. 1992 Dec;327(23):1649-62.

7. Telfer NR, Colver GB, Morton CA; British Association of Dermatologists. Guidelines for the management of basal cell carcinoma. Br J Dermatol. 2008 Jul;159(1):35-48.

8. Bussu F, Tagliaferri L, Mattiucci G, Parrilla C, Dinapoli N, Micciche F, et al. Comparison of interstitial brachytherapy and surgery as primary treatments for nasal vestibule carcinomas. Laryngoscope. $2016 \mathrm{Feb}$; 126(2):367-71.

9. Federspil PA. Ear epistheses as an alternative to autogenous reconstruction. Facial Plast Surg. 2009 Aug;25(3):190-203.

10. Wray J, Morris CG, Kirwan JM,Amdur RJ, Werning JW, Dziegielewski PT, et al. Radiation therapy for nasal vestibule squamous cell carcinoma: a 40-year experience. Eur Arch Otorhinolaryngol. 2016 Mar;273(3):661-9.

11. Veness MJ, Chong L, Tiver K, Gebski V. Basal cell carcinoma of the nose: an Australian and New Zealand radiation oncology patterns-ofpractice study. J Med Imaging Radiat Oncol. 2008 Aug;52(4):382-93.

12. Sedda AF, Rossi G, Cipriani C, Carrozzo AM, Donati P. Dermatological high-dose-rate brachytherapy for the treatment of basal and squamous cell carcinoma. Clin Exp Dermatol. 2008 Nov;33(6):745-9.

13. Henry EL, Hart RD, Mark Taylor S, Trites JR, Harris J, O'Connell $\mathrm{DA}$, et al.Total nasal reconstruction: use of a radial forearm free flap, titanium mesh, and a paramedian forehead flap. J Otolaryngol Head Neck Surg. 2010 Dec;39(6):697-702.

14. Jeremic G, Brandt MG, Jordan K, Doyle PC, Yu E, Moore CC. Using photodynamic therapy as a neoadjuvant treatment in the surgical excision of nonmelanotic skin cancers: prospective study. J Otolaryngol Head Neck Surg. 2011 Feb;40 Suppl 1:S82-9.

15. Kim HJ, Lee KH, Park SY, Kim HK. One-stage reconstruction for midfacial defect after radical tumor resection. Clin Exp Otorhinolaryngol. 2012 Mar;5(1):53-6.

16. Park SS. Nasal reconstruction in the 21st century: a contemporary review. Clin Exp Otorhinolaryngol. 2008 Mar;1(1):1-9.

17. van der Eerden PA, Prins ME, Lohuis PJ, Balm FA, Vuyk HD. Eighteen years of experience in Mohs micrographic surgery and conventional excision for nonmelanoma skin cancer treated by a single facial plastic surgeon and pathologist. Laryngoscope. 2010 Dec;120(12): 2378-84.

18. Wollina U, Bennewitz A, Langner D. Basal cell carcinoma of the outer nose: overview on surgical techniques and analysis of 312 patients. J Cutan Aesthet Surg. 2014 Jul;7(3):143-50.

19. Zaoui K, Thielen HM, Plath M, Baumann I, Plinkert PK, Federspil PA. Quality of life after nasal cancer resection: surgical versus prosthetic rehabilitation. Rhinology. 2018 Dec;56(4):400-6.

20. Zaoui K, Plinkert PK, Federspil PA. Primary surgical treatment of nasal vestibule cancer: therapeutic outcome and reconstructive strategies. Rhinology. 2018 Dec;56(4):393-9.

21. Bulut OC, Plinkert PK, Wallner F, Baumann I. Quality of life in functional rhinoplasty: rhinoplasty outcomes evaluation German version (ROE-D). Eur Arch Otorhinolaryngol. 2016 Sep;273(9):2569-73. 
22. Bulut OC, Wallner F, Plinkert PK, Prochnow S, Kuhnt C, Baumann I. Quality of life after septorhinoplasty measured with the Functional Rhinoplasty Outcome Inventory 17 (FROI-17). Rhinology. 2015 Mar;53(1):54-8.

23. Rohrich RJ, Griffin JR, Ansari M, Beran SJ, Potter JK. Nasal reconstruction--beyond aesthetic subunits: a 15-year review of 1334 cases. Plast Reconstr Surg. 2004 Nov;114(6):1405-16.

24. Han DH, Mangoba DC, Lee DY, Jin HR. Reconstruction of nasal alar defects in asian patients. Arch Facial Plast Surg. 2012 Sep-Oct; 14(5):312-7.

25. Kim YJ, Cho HH, Kim SO, Lee JB, Lee SC. Reconstruction algorithm for nasal basal cell carcinoma with skin involvement only: analysis of 221 cases repaired by minor surgery. Clin Exp Dermatol. 2015 Oct;40(7):728-34.

26. Moolenburgh SE, Mureau MA, Duivenvoorden HJ, Hofer SO. Validation of a questionnaire assessing patient's aesthetic and functional outcome after nasal reconstruction: the patient NAFEQ-score. J Plast Reconstr Aesthet Surg. 2009 May;62(5):656-62.

27. Becker C, Becker AM, Dahlem KK, Offergeld C, Pfeiffer J. Aesthetic and functional outcomes in patients with a nasal prosthesis. Int $\mathrm{J}$ Oral Maxillofac Surg. 2017 Nov;46(11):1446-50.

28. Becker C, Becker AM, Pfeiffer J. Health-related quality of life in patients with nasal prosthesis. J Craniomaxillofac Surg. 2016 Jan;44(1): 75-9.
29. NoelW, Duron JB, Jabbour S, Revol M, Mazouz-Dorval S.Three-stage folded forehead flap for nasal reconstruction: objective and subjective measurements of aesthetic and functional outcomes. J Plast Reconstr Aesthet Surg. 2018 Apr;71(4):548-56.

30. Hassan SJ, Weymuller EA Jr. Assessment of quality of life in head and neck cancer patients. Head Neck. 1993 Nov-Dec;15(6):485-96.

31. Rogers SN, Gwanne S, Lowe D, Humphris G, Yueh B,Weymuller EA $\mathrm{Jr}$. The addition of mood and anxiety domains to the University of Washington quality of life scale. Head Neck. 2002 Jun;24(6):521-9.

32. Bulut C, Wallner F, Plinkert PK, Baumann I. Development and validation of the Functional Rhinoplasty Outcome Inventory 17 (FROI17). Rhinology. 2014 Dec;52(4):315-9.

33. Alsarraf R, Larrabee WF Jr, Anderson S, Murakami CS, Johnson CM Jr. Measuring cosmetic facial plastic surgery outcomes: a pilot study. Arch Facial Plast Surg. 2001 Jul-Sep;3(3):198-201.

34. Saleh AM, Younes A, Friedman O. Cosmetics and function: qualityof-life changes after rhinoplasty surgery. Laryngoscope. 2012 Feb; 122(2):254-9.

35. Hellings PW, Nolst Trenite GJ. Long-term patient satisfaction after revision rhinoplasty. Laryngoscope. 2007 Jun;117(6):985-9.

36. Faidiga GB, Carenzi LR, Yassuda CC, Silveira F, Lago Td, Leite MG, et al. Long-term evaluation in aesthetic rhinoplasty in an academic referral center. Braz J Otorhinolaryngol. 2010 Jul-Aug;76(4):437-41. 